\title{
Health Practices, Risk Factors, and Chronic Disease in Tecumseh ${ }^{1}$
}

\author{
Helen L. Metzner, * Wendy J. Carman, ${ }^{*}$ and James House $\dagger$ \\ *Department of Epidemiology, School of Public Health, and †Departments of Sociology, \\ Epidemiology, and Survey Research Center, University of Michigan, 109 Observatory Street, \\ Ann Arbor, Michigan 48109
}

Seven health practices previously found to be associated with a self-report index of good health and with lower mortality in the Alameda County studies were related to several measures of health in a cohort of 880 men and 973 women, ages 35-69, who were participants in the Tecumseh Community Health Study. The health measures were prevalence of three diagnoses-coronary heart disease (CHD), hypertension, and chronic bronchitisand levels of five risk factors-systolic and diastolic blood pressures, serum total cholesterol, blood glucose, and $\mathrm{FEV}_{1}$. Four of the practices-desirable relative weight, physical activity, never having smoked, and moderate or no alcohol drinking-were associated significantly with one or more of the health measures. Eating breakfast, limited between-meal eating, and sleeping 7 or $8 \mathrm{hr}$ were not related to the health measures. Combining all seven health practices into an index produced a measure that was more strongly associated negatively with CHD prevalence than was any one of the component practices. However, the index was no more strongly associated with any of the other health measures than were the relevant separate practices. Desirable weight was more highly associated (negatively) with hypertension and blood pressure than the index was, as was never having smoked with chronic bronchitis (negatively) and $\mathrm{FEV}_{1}$ (positively).

For over 50 years, health authorities have urged the public to adopt a "healthy" lifestyle composed of those specific habits or practices of daily living that have been clinically observed to be related to the absence of selected illnesses. "Healthy" habits include, among others, a regular eating schedule, eating breakfast, an adequate but not excessive caloric intake, sleeping about $8 \mathrm{hr}$ daily, regular exercise, not smoking cigarettes, and moderate or no drinking of alcoholic beverages. Within the last 15 years, several published articles from the Alameda County, California Human Population Laboratory have reported on systematic studies of the relationship of these "healthy" habits or personal health practices to overall health status and mortality in a general population. In cross-sectional analyses, seven health practices were positively associated to a small degree individually, and to a larger degree cumulatively, with an index of physical health status $(1,2)$; in longitudinal analyses, they were associated with overall health status 9 years later and to mortality ascertained $5 \frac{1 / 2}{2}$ and $91 / 2$ years later $(3,4,22)$. Although the reports generated much interest and stimulated renewed efforts to modify the public's behavior in the directions indicated, there appears to be only one published study that tried to substantiate in another population the relationships found for all seven practices and the index (21).

${ }^{1}$ Supported in part by Grants HL 24545, HL 18632, and HL 09814 from the National Heart, Lung, and Blood Institute, National Institutes of Health, U.S. Public Health Service. 
Data from the Tecumseh Community Health Study afforded an opportunity to investigate whether similar relationships would be found in a different general population. This article presents the results of a cross-sectional analysis of the Tecumseh data relating similar personal health practices to three measures of chronic disease and to five risk factors for these conditions. Although not an exact replication of the Alameda County studies, the present analysis is similar enough in concepts, measures, and methods of analysis for this report to be considered a serious effort at substantiation of the Alameda County results. It also represents an extension of the Alameda County analysis, because it shifts the focus of the relationship of health status to health practices away from a general measure of health to specific measures, and away from a solely self-report of data to a combination of respondents' reports and anthropometric and physiologic measures. This report also discusses whether indexing the practices into a single measure adds any more information to the association between the health practices and health status than is contributed by the separate practices.

A subsequent report will relate the same practices to mortality 9 to 12 years later.

\section{METHODS}

The Tecumseh study is a longitudinal epidemiological study of the health of residents of a small community in southeastern Michigan $(8,15)$. The study started in 1957 and has collected data on several occasions since 1959 involving, at various times, all residents, accessible former residents who had been participants, and subsets of these groups. The response rates from the first two major series of interviews and examinations involving all residents were 88\% in 1959-1960 and $82 \%$ in 1962-1965. The analysis reported here is based on data from men and women ages 35-69 who were interviewed and examined in the third series, during the period 1967-1969. The study population eligible to be examined in the third series consisted of a cohort of 3,873 persons who were previously examined at least once and who were still alive, and persons who were not previously examined but were in a $10 \%$ dwelling unit sample of current residents of the community. Of the eligible population, $71 \%$ or 2,754 men and women, were actually interviewed and examined. The nonrespondent portion comprised $11 \%$, or 442 persons, who were found to have left the area; $2 \%$, or 60 persons, who could not be located at the time of data collection; and $16 \%$, or 617 persons, who were in the study area but refused to participate or were temporarily unavailable.

Several kinds of data were collected in the third series, but, in accordance with a complicated study design, not everyone was eligible for all the different interviews and procedures. Since the analysis to be reported here required data from several interview forms and procedures, including an interview on sleeping and eating habits administered to a random sample of only two-thirds of the study group, the population for this report is $1,855,882$ men and 973 women. A description of the order and method of interviewing in the Tecumseh study has been more fully presented elsewhere (15). 


\section{Health Practices}

The seven health practices described below were all made dichotomous in order to approximate the variables used in the Alameda County study as closely as possible. The first three variables were derived from the daily activities and 24hr food intake recall interview. (a) Eats breakfast. This variable was based on answers to the question, "Do you usually have something to eat early in your day's activities?" The immediately preceding question was, "What time do you usually get up on weekdays (days that you work)?" There were a number of shift workers in the community and we sought to avoid differing names for the first meal which, for late-shift workers, occasionally was "dinner" with the rest of the family. In this study, the first meal was equated with breakfast. (b) No evening snack. This variable describes snacking only between the last meal of the day and bedtime and was ascertained by the question, "Do you usually have something to eat or drink between your evening (last) meal and going to bed?" Of all seven health practices, this one least resembles the parallel one from the Alameda County study, which asked about frequency of eating between (all) meals. (c) Sleeps 7-8 hr. This variable was derived by subtracting reported usual time of arising from reported usual bedtime. (d) Relative weight. Weight, measured in the clinic, was divided by the square of height and multiplied by a constant to give an index of 100 to the midpoint of the desirable weight for height (weight associated with the lowest mortality) from the Tables of the Metropolitan Life Insurance Company (12). The index is observed weight as a percentage of desirable weight. The distributions for men and women were then dichotomized according to the definitions used in the Alameda County studies. Men who were classed at desirable weight were between less than $5 \%$ underweight and less than $20 \%$ overweight. Women who were defined at desirable weight were less than $10 \%$ overweight. (e) Physically active. There are two measures for this variable for men and one for women. Detailed information was obtained for men by interviewers questioning about frequency and time spent in the past year in 23 different physically active leisure activities, ranging in effort from bowling, with a work metabolism to basal metabolism ratio of 3.0 , to snow skiing with a ratio of $8.0(14,18)$. The 23 activities included the more common forms of recreation as walking, dancing, swimming, and golf, as well as other less frequent recreations. The average number of hours spent per week in physically active leisure were summed for each respondent, and a frequency distribution was obtained for the study group. The distribution was dichotomized so that the "active" category, containing $31 \%$ of the men, was defined as spending an average of 7 or more hours per week in one or more of the 23 listed activities. This measure was called physically active 1 . Since the data for this measure were not collected for women, another measure was developed that was applicable to both men and women. Prior to the detailed interview, both women and men were asked whether they participated once or more often during the past year in each of the same 23 activities. The number of activities participated in was summed and the distribution dichotomized at about the median for all men who answered these questions. The result was that $55 \%$ of the men and $34 \%$ of the women had participated 
in five or more activities and were classed as "physically active." Since this measure, called physically active 2, gives equal weight to participating in an activity once for a short time and to spending several hours a week at it regularly, it cannot be considered as good a measure of expended effort as physically active 1. (f) Never smoked cigarettes. Information for this variable and the drinking variable, (g) drinks less than five drinks a day, came from the self-administered health history questionnaire.

\section{Health Measures}

The measures of health used as dependent variables were three diagnoses(a) coronary heart disease (CHD), which was defined as probable history of myocardial infarction or angina, or electrocardiographic evidence of myocardial infarction (Minnesota codes 1-1 or 1-2); (b) hypertension, defined as blood pressure levels found, on examination, equal to or greater than $160 \mathrm{~mm}$ systolic or $95 \mathrm{~mm}$ diastolic, fifth phase, or the response that "blood pressure medicine" was currently being taken; (c) chronic bronchitis, defined as the reporting of cough and phlegm in the morning and during the day or at night for at least 3 months of the year-and five risk factors-(d) systolic and (e) diastolic, fifth phase, blood pressure levels found on examination; casual measures of (f) serum cholesterol determined by autoanalyzer; (g) blood glucose determined by an autoanalyzer using the modified Hoffman method; and (h) $F E V_{1}$ score, forced expiratory volume in the first second adjusted for sex, age, and height using the $\mathrm{FEV}_{1}$ values of nonsmoking respondents without respiratory disease or symptoms. $(6,8,9$, $16,17)$.

It is apparent that all of the eight health measures are not independent. In fact, hypertension was defined in terms of the blood pressure values found on examination. Also systolic and diastolic blood pressure are related to one another, as are blood pressure and cholesterol to CHD, and FEV 1 to chronic bronchitis. All the measures were included individually in this analysis as each has considerable variance not explained by any of the others, and each has been found to be related to mortality or to the etiology of chronic disabling disease.

\section{Statistical Analysis}

Statistical analysis employed contingency table analysis and analysis of variance and covariance. Age was adjusted by the direct method when relating the diagnoses to the health practices and the health practice index. When this adjustment did not materially alter the relationships observed, chi-square was used on the unadjusted data to test the associations. However, where age adjustment substantially affected the association, the Mantel-Haenszel method for average partial association (11) was used. Analysis of covariance, with age as the covariate, was used to test the association between four of the five risk factors and the health practices and the health practice index. Analysis of variance was used for the fifth risk factor, $\mathrm{FEV}_{1}$, which was an age-adjusted score. 


\section{RESULTS}

\section{Individual Health Practices}

The distributions of the health practices in the study population are to be found in Table 1. Somewhat comparable Alameda County percentages are also presented; however, it must be emphasized that the kind of data, the questions, and the classification of the Alameda County data are different for six of the seven practices. Only smoking is directly comparable.

Both studies report similar percentages of men and women with good sleep, smoking, and drinking practices. A much smaller percentage of Alameda County than Tecumseh respondents report eating breakfast regularly. There is also a marked difference in the amount of snacking reported in the two studies. About $75 \%$ of the Alameda County subjects reported not eating between meals during any part of the day. Between 35 and $45 \%$ of the Tecumseh respondents said they did not snack in the evening. Presumably, these percentages would be even smaller if we knew about the between meal eating for other parts of the day.

Tecumseh men and women are generally heavier than their Alameda County counterparts. Less than $50 \%$ of the Tecumseh men are at a desirable relative weight, $19 \%$ fewer than similar-aged men in Alameda County, and only $30 \%$ of the Tecumseh women are so classified compared with $59 \%$ of the Alameda County women. Many fewer Tecumseh than Alameda County men and women are classified as physically active; the dissimilarity is probably related to a great degree to the difference in how the practice was defined. The Tecumseh physically active 1 measure reflects an average number of hours a week in all energetic leisure activities reported by the men for themselves and, as such, is an indication of relative effort expended in leisure, whereas the Alameda County measure is a qualitative evaluation of the frequency of only a few energetic activities. The Tecumseh physically active 2 measure reflects simple participation in leisure activities and, therefore, may be as much a measure of social as of physical activity.

The relationships of individual health practices to several measures of healththe diagnoses of $\mathrm{CHD}$, hypertension, and chronic bronchitis, and the five risk factors - can be seen in Tables $2 a$ and $b$. Among men and women, only four of the health practices-desirable weight, physically active 2 , never smoked, and moderate or no drinking - related to the health measures as expected (positively with $\mathrm{FEV}_{1}$ and negatively with the others), considering the direction of both absolute and significant differences. Physically active 1 did not relate to the health practices as expected (in the "correct" direction two out of eight times and significantly once in the "wrong" direction) nor as well as physically active 2 . Consequently, physically active 2 was selected as the activity measure to be used in the health practices index. In this study group, eating breakfast related slightly negatively to poor health status among women but not among men. This variable had extremely limited variance and consequently may not be likely to discriminate. However, no evening snack and sleeping 7-8 hr a day, variables with good variances, also did not relate as expected, negatively, for both men and women, 


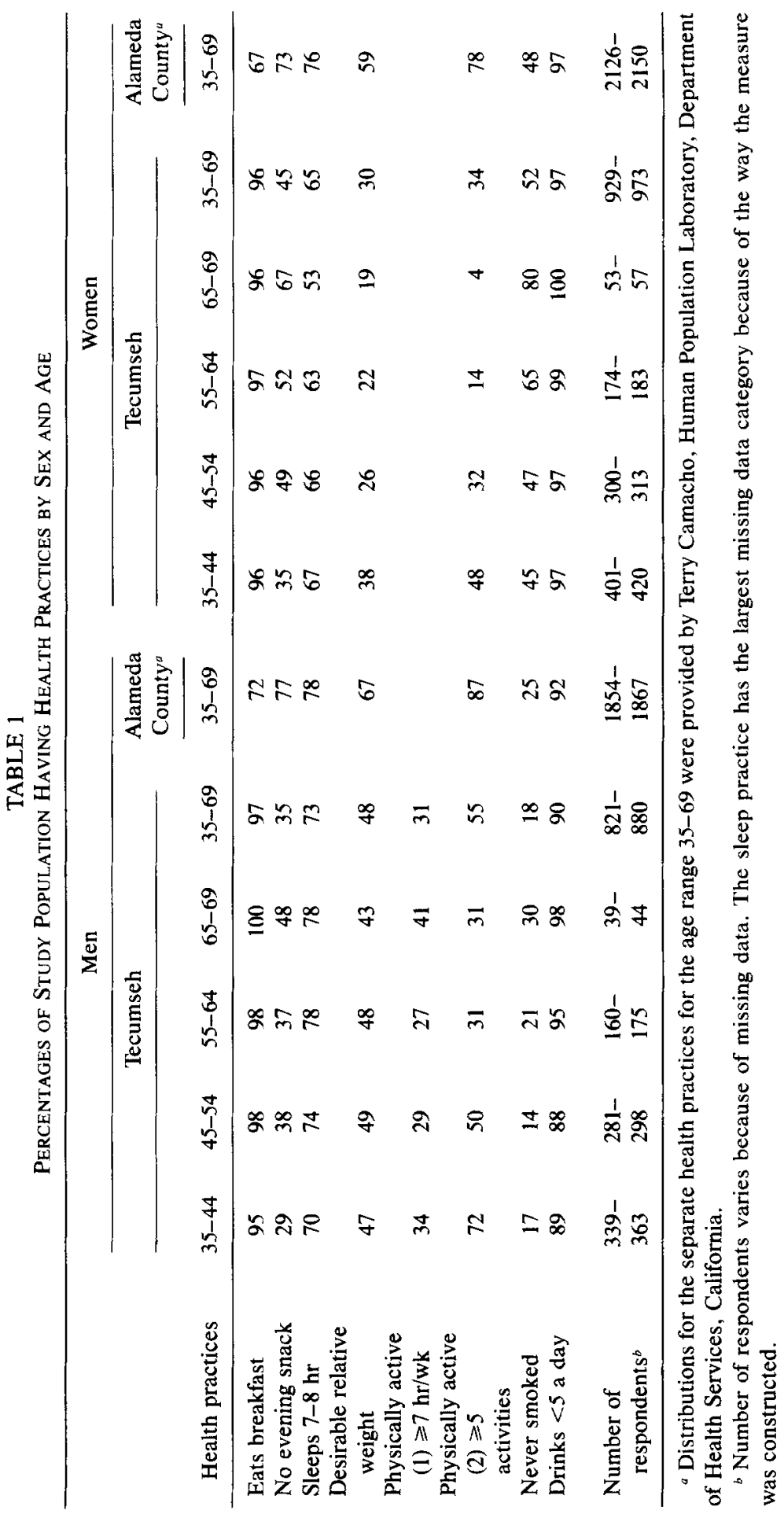




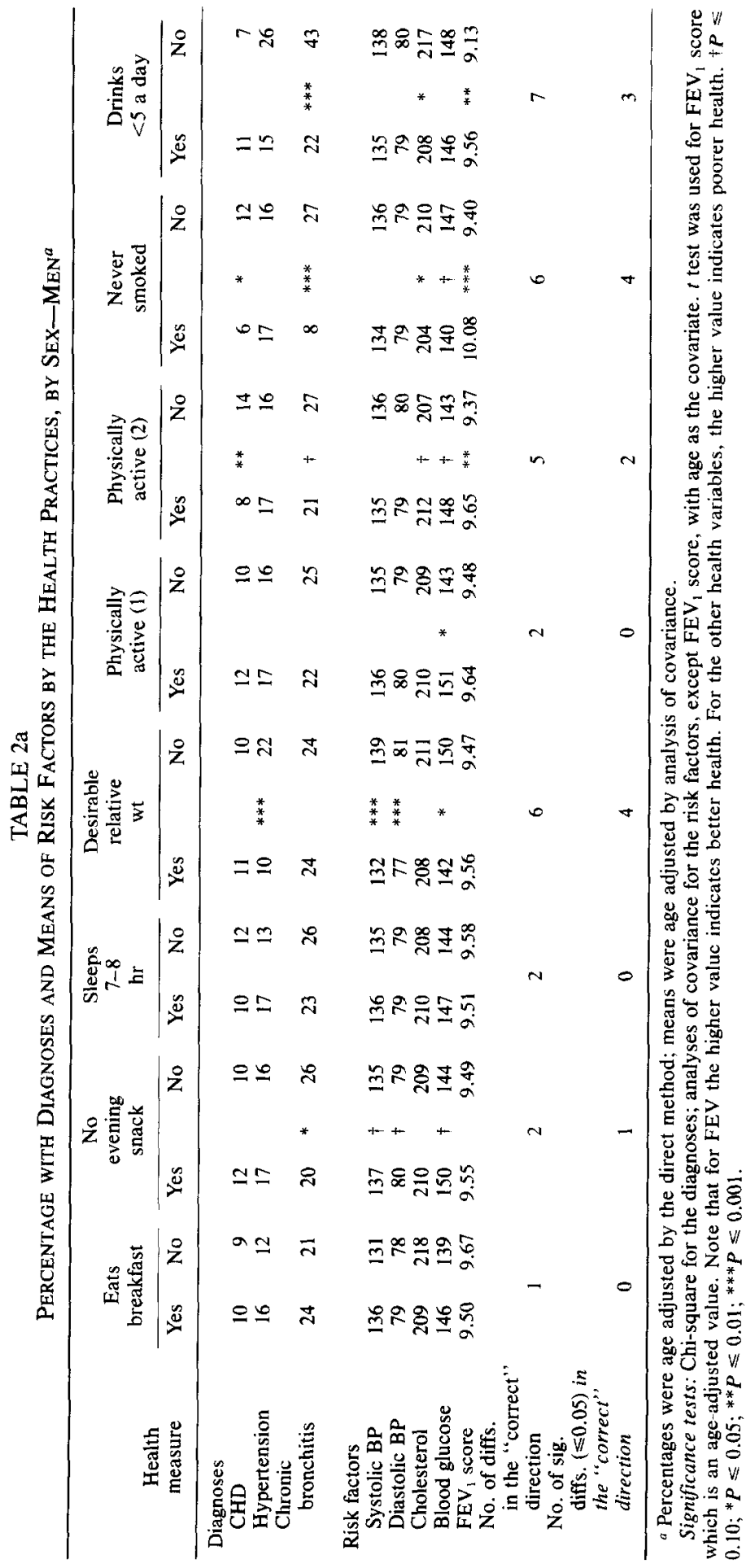




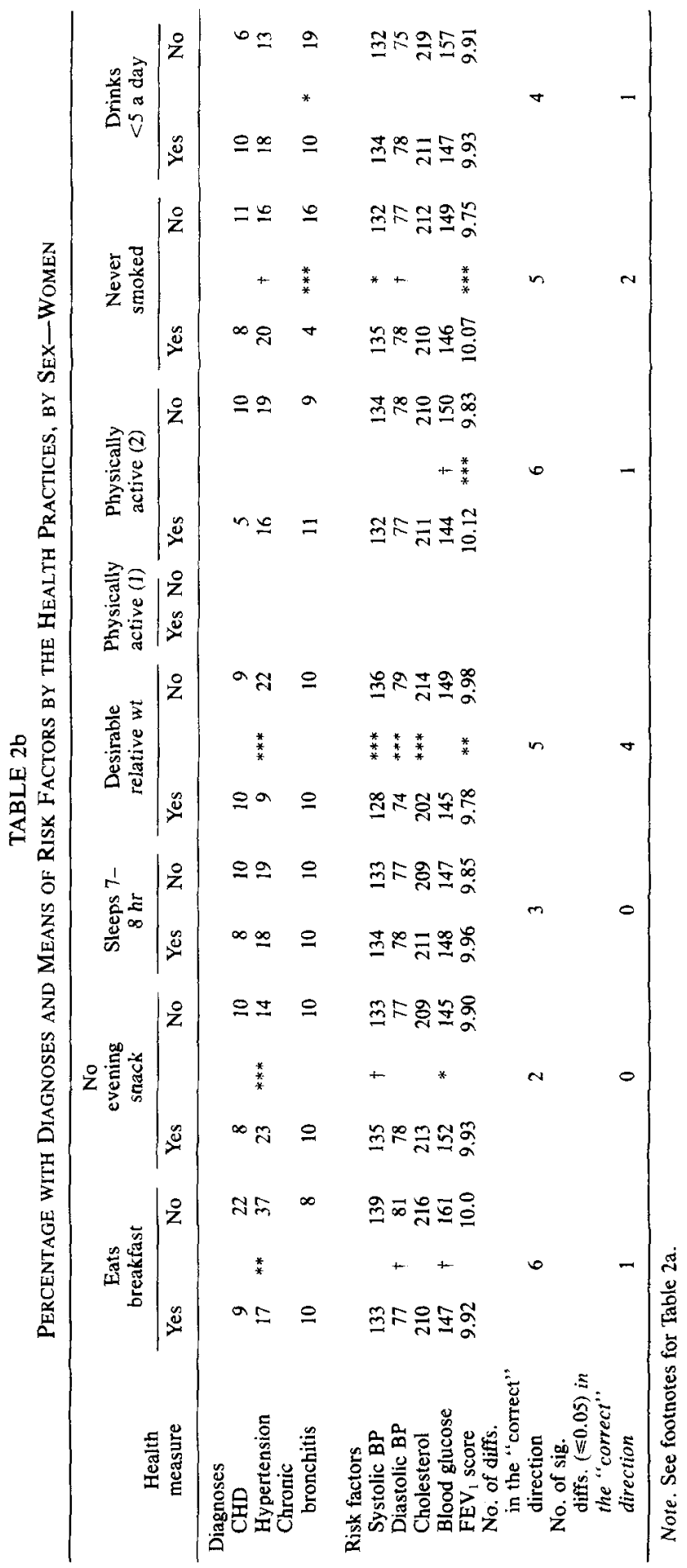


and a low variance measure, drinks $<5$ a day, did discriminate. Thus, the results for eating breakfast do not appear to be an artifact of low variance.

\section{Health Practice Index}

The seven health practices were combined into an additive index as was done in the Alameda County studies. The $12 \%$ who had missing data for one or more practices were omitted. The values range from 0 , no health practices, to 7 , all health practices. Low frequencies were found at either end of the index; $1 \%$ of the study group had zero practices or one, about $5 \%$ had two, and almost $2 \%$ had seven. Consequently, in most analyses, the categories were collapsed at both ends of the scale. When the distributions of the index for each sex were compared among four age groups, 35-44, 45-54, 55-64, and 65-69, there were no ageassociated differences. Table 3 shows that the index is distributed substantially the same among Tecumseh men as among women; the Alameda County index is also distributed the same among Alameda County men and women. Differences between the Tecumseh and Alameda County index distributions probably are due largely to the differences between the two groups in their distributions for several of the component health practices, as discussed earlier.

The health practices index is significantly related in the expected direction $(P$ $\leqslant 0.05$ ) to two diagnoses and two risk factors among men and to one risk factor among women (Table 4). However the index relates negatively to all three diagnoses, CHD, hypertension, and chronic bronchitis, in men and women at the $P$ $\leqslant 0.10$ significance level.

In further analyses of these relationships within sex-age groups, the health practices index was dichotomized because of small numbers in the sex-age groups. Among men in each age group, those who had an index score of $0-4$ consistently

TABLE 3

Distribution of the Health Practices Index by SeX

\begin{tabular}{|c|c|c|c|c|c|c|c|c|}
\hline \multirow{3}{*}{$\begin{array}{l}\text { Health } \\
\text { practices } \\
\text { index }\end{array}$} & \multicolumn{4}{|c|}{ Men } & \multicolumn{4}{|c|}{ Women } \\
\hline & \multicolumn{2}{|c|}{ Tecumseh } & \multicolumn{2}{|c|}{$\begin{array}{c}\text { Alameda } \\
\text { County }\end{array}$} & \multicolumn{2}{|c|}{ Tecumseh } & \multicolumn{2}{|c|}{$\begin{array}{c}\text { Alameda } \\
\text { County }\end{array}$} \\
\hline & $N$ & $\%$ & $N$ & $\%$ & $N$ & $\%$ & $N$ & $\%$ \\
\hline 3 or less & 206 & 26 & 223 & 12 & 227 & 26 & 278 & 13 \\
\hline 4 & 284 & 37 & 415 & 22 & 293 & 34 & 437 & 20 \\
\hline 5 & 191 & 25 & 558 & 30 & 257 & 30 & 672 & 31 \\
\hline 6 & 84 & 11 & 504 & 27 & 85 & 10 & 347 & 25 \\
\hline 7 & 12 & 2 & 172 & 9 & 9 & 1 & 220 & 10 \\
\hline \multicolumn{9}{|c|}{ Dichotomized } \\
\hline 4 or less & 490 & 63 & 638 & 34 & 520 & 60 & 715 & 33 \\
\hline $5-7$ & 287 & 37 & 1234 & 66 & 351 & 40 & 1439 & 67 \\
\hline Total & 777 & & 1872 & & 871 & & 2154 & \\
\hline N.A. & 105 & & & & 102 & & & \\
\hline
\end{tabular}

ages 35-69. 
TABLE 4

Percentage with Diagnoses and Means of Risk Factors by the Health Practice Index, for All Ages 35-69 Combined, Age-Aduusted, ${ }^{a}$ By SeX

\begin{tabular}{|c|c|c|c|c|c|c|c|c|c|c|}
\hline \multirow[b]{3}{*}{$\begin{array}{l}\text { Health } \\
\text { measure }\end{array}$} & \multicolumn{10}{|c|}{ Health practice index } \\
\hline & \multicolumn{5}{|c|}{ Men } & \multicolumn{5}{|c|}{ Women } \\
\hline & $0-3$ & 4 & 5 & $\begin{array}{c}6 \\
\text { and } \\
7\end{array}$ & Sig. & $0-3$ & 4 & 5 & $\begin{array}{c}6 \\
\text { and } \\
7\end{array}$ & Sig. \\
\hline \multicolumn{11}{|c|}{ Percentages } \\
\hline \multicolumn{11}{|l|}{ Diagnoses } \\
\hline CHD & 14 & 12 & 8 & 5 & $\leqslant 0.10$ & 12 & 10 & 7 & 4 & $\leqslant 0.10$ \\
\hline $\begin{array}{l}\text { Hypertension } \\
\text { Chronic }\end{array}$ & 16 & 19 & 14 & 7 & $\leqslant 0.05$ & 20 & 19 & 20 & 8 & $\leqslant 0.10$ \\
\hline bronchitis & 30 & 27 & 25 & 2 & $\leqslant 0.001$ & 13 & 11 & 8 & 4 & $\leqslant 0.10$ \\
\hline \multicolumn{11}{|c|}{ Means } \\
\hline Risk factors & & & & & & & & & & \\
\hline Systolic BP & 136 & 137 & 134 & 131 & $\leqslant .05$ & 134 & 134 & 135 & 131 & N.S. \\
\hline Diastolic BP & 79 & 80 & 79 & 78 & N.S. & 78 & 78 & 78 & 75 & N.S. \\
\hline $\begin{array}{l}\text { Cholesterol } \\
\text { Blood }\end{array}$ & 208 & 211 & 208 & 209 & N.S. & 211 & 214 & 207 & 210 & N.S. \\
\hline glucose & 145 & 147 & 146 & 143 & N.S. & 151 & 148 & 145 & 149 & N.S. \\
\hline FEV $_{1}$ score & 9.30 & 9.54 & 9.60 & 9.96 & $\leqslant 0.001$ & 9.79 & 9.95 & 9.94 & 10.28 & $\leqslant 0.001$ \\
\hline Number ${ }^{b}$ & 206 & 284 & 191 & 96 & & 227 & 293 & 257 & 94 & \\
\hline
\end{tabular}

a Percentages are age adjusted by direct standardization; means other than the FEV score are adjusted by analysis of covariance; the FEV score is an age-adjusted measure.

$b$ These are maximum values. Some of the larger groups may be smaller by 11 because of missing data.

Significance tests: Percentages: chi-square on the unadjusted values which are the same in integers as the adjusted values. Means: analysis of covariance except for FEV scores; analysis of variance for FEV scores.

had a larger percentage with each of the three diagnoses, but these associations were significant $(P \leqslant 0.05)$ in only two age and diagnosis comparisons. When these comparisons by age group were cumulated for each diagnosis and tested by the Mantel-Haenszel test for average partial association (11), the index was significantly related negatively to all three diagnoses among men (Table 5). Among women, 9 out of 12 possible age-diagnosis comparisons were in the "correct" or predicted direction and only one significant relationship was found within age groups. However, similar application of the Mantel-Haenszel test indicated that the index was significantly related to CHD and chronic bronchitis over all age groups.

The dichotomized index was not consistently related to the risk factors. Although for men, a low index score was associated with a poorer risk factor level in 19 out of 20 risk factor-age group comparisons, and for women, in 15, statistical 


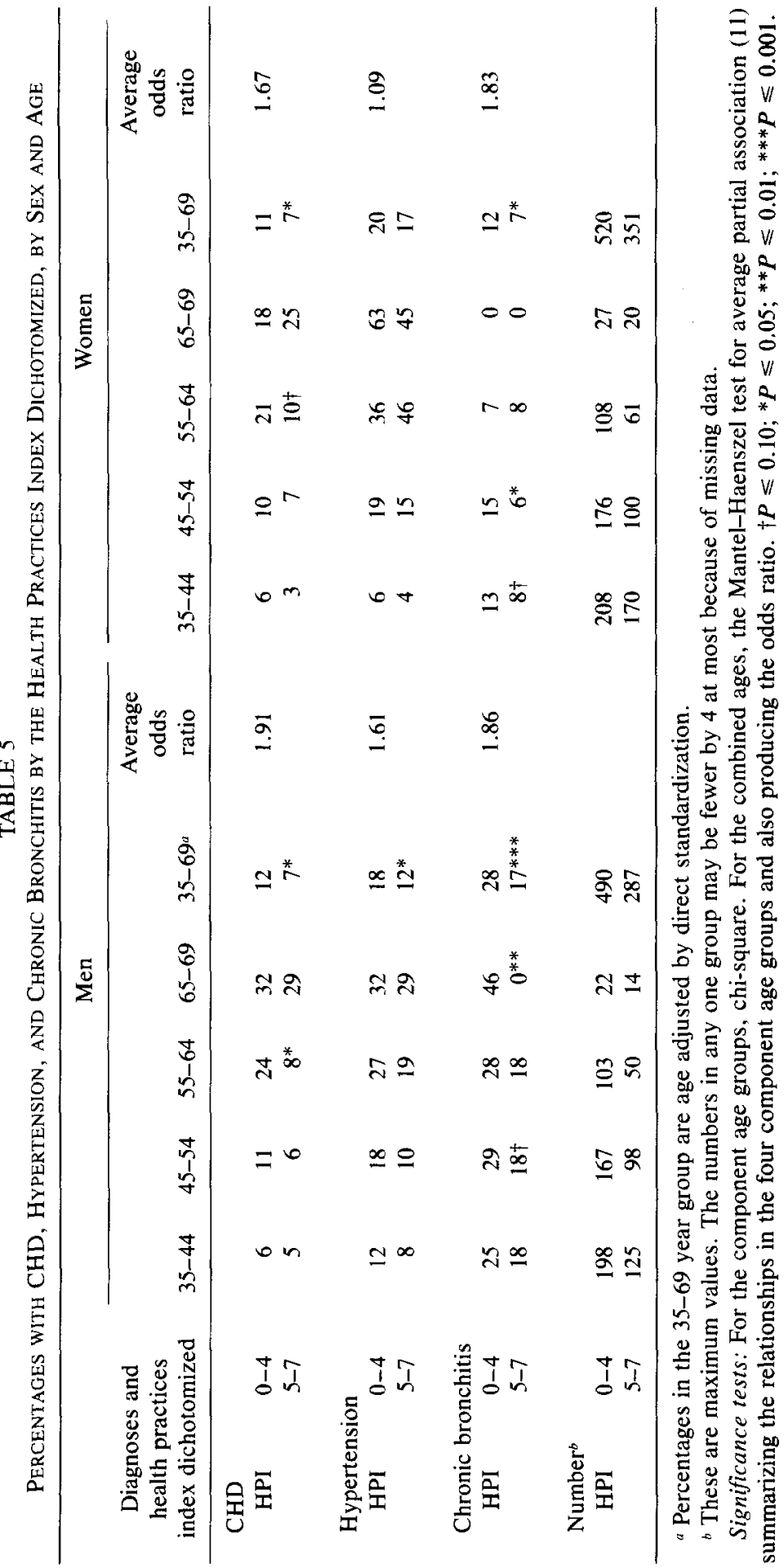


significance $(P \leqslant 0.05)$ within risk factor-age group was scattered and occurred only twice in 20 possibilities each for men and women (Table 6). However, the dichotomous index was significantly associated, as predicted, among men ages 35-69 negatively with systolic blood pressure and positively with $\mathrm{FEV}_{1}$ score and among women 35-69 negatively with serum cholesterol and positivcly with FEV, score.

In summary, the health practice index in the four-category and dichotomized forms was associated with some of the health status measures, and most consistently negatively with chronic bronchitis and positively with the $\mathrm{FEV}_{1}$ scores. The four-category index was significantly related $(P \leqslant 0.05)$ negatively among men to hypertension and systolic blood pressure. Among men and women, the index was related to CHD only when dichotomized. Additionally, among women, the dichotomized index was related significantly negatively to serum cholesterol. These relationships were also found within sex-age groups but infrequently at statistically significant levels.

\section{DISCUSSION}

The analysis described was undertaken to investigate whether the findings in the Alameda County study could be constructively replicated (i.e., replicated with different measures of the same concepts) and extended using data from another general population, from another region, with differently derived health practice measures, and a set of entirely different health status measures. In the Alameda County study, the health practices and health status measures were obtained from a mail-in, self-administered questionnaire. The health practices were derived from answers to questions about weight, height, usual hours of sleep, frequency of eating breakfast and between meals, selected active free-time activities, frequency and amount of alcohol consumption, and cigarette smoking practices. The health status measure was a seven-category index "ranging from severe disability to a condition without disability, impairments, chronic conditions or symptoms and with great vigor" (2) which was developed from 11 questions concerned with "ability to perform certain basic daily activities; presence during the last 12 months of one or more chronic conditions or impairments; presence during the last 12 months of one or more symptoms; and subjective rating of general energy level" (1). In the Tecumseh study, the health practices and health status measures came from a variety of sources including direct self-response, derived measures from interviewer administered questions, anthropometric measures, laboratory tests, and physicians' diagnoses. The eight health status measures were specific aspects of health. The Alameda County study encompassed persons 20 years of age and older in a probability sample of an urbanized California county. The Tecumseh study population was limited to a 35- to 69-year-old cohort of the original study and a $10 \%$ dwelling unit sample of the Michigan community of 10,000 residents. About $16 \%$ of the Alameda County study population was nonwhite, whereas there were practically no nonwhites in the Tecumseh study population.

Given these differences, it is interesting that, in general, the Tecumseh study findings do substantiate the Alameda County results $(2,20)$. Although none of 


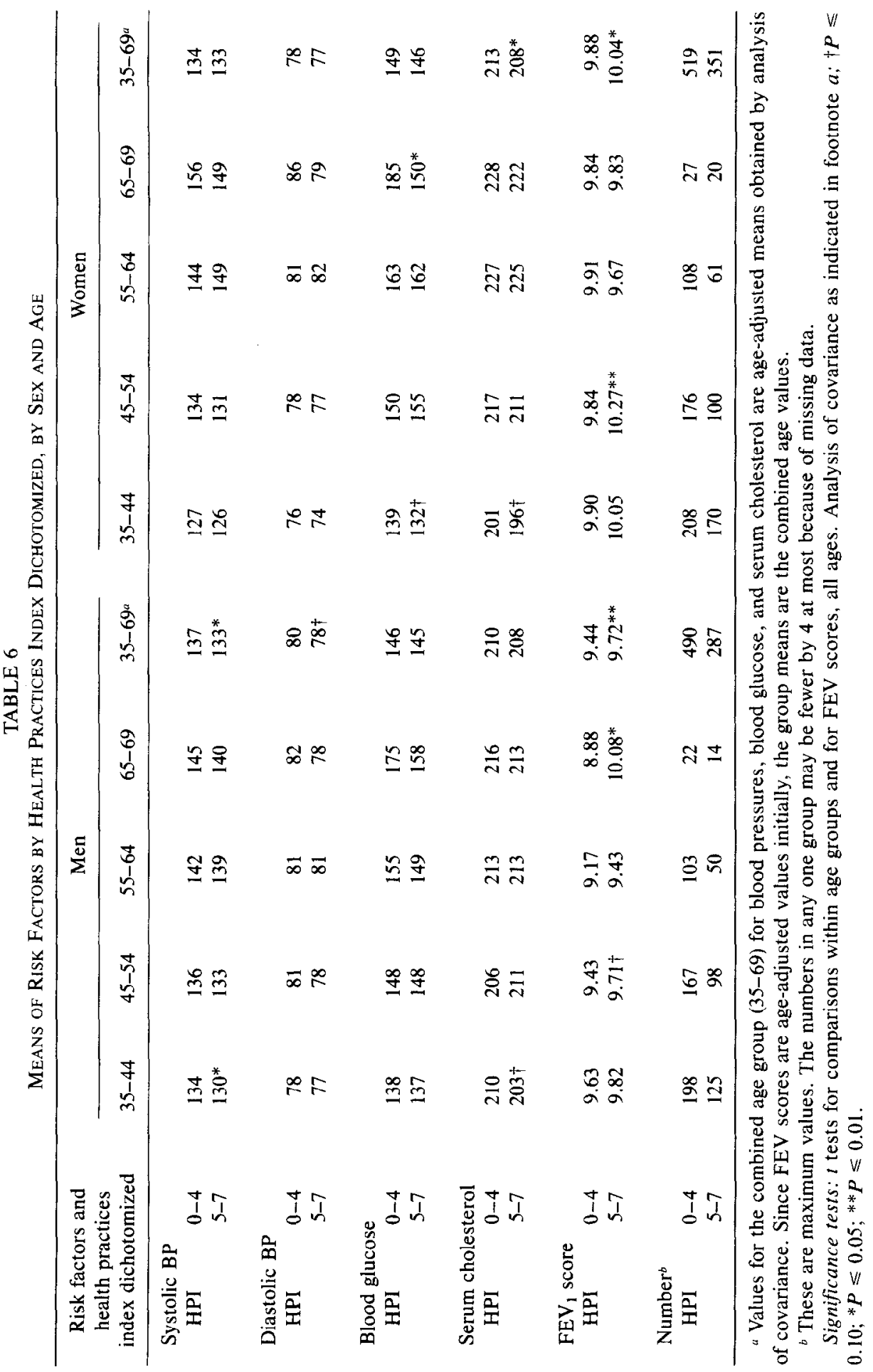


the health practices are strongly related to all of the health measures in the Tecumseh study, six are significantly related to one or more health measures, and five of the seven show tendencies in the predicted direction (over one-half of the differences for either sex are in the predicted direction). Both studies found that desirable relative weight was significantly related to the various health status measures. In the Tecumseh study, desirable relative weight was related in the predicted direction with six of the eight health measures among men, four significantly, and with five among women, four also significantly. Both studies found moderate or no drinking an important health practice; not smoking was more important in the Tecumseh data.

"Physical activity" was an important behavior in both studies, but it is apparent from the Tecumseh analysis that this variable may reflect more social activity than energy output. The physically active 1 measure, which categorizes the reported amount of time spent in active leisure and is, therefore, more an indicator of energy output than social activity, did not relate at all significantly to the health status measures nor to mortality $9^{1 / 2}$ years later in a multivariate analysis done for an earlier report (10). There were indications that the social participation aspect of leisure activities was also important in the Alameda County study. Belloc and Breslow (2) reported that taking weekend automobile trips also related to physical health status but because this activity was not "clearly physical activity," they excluded it from their final measure. Another analysis of Alameda County data shows this relationship in greater detail (5). The association of the physically active 2 measure with health status measures also appears to be part of a more general pattern of association between social activity and health in the Tecumseh study, as described elsewhere (10).

Sleep was found to be significant in the Alameda County study but not in the Tecumseh study. Both studies found that eating breakfast did not have an important association with health status cross-sectionally. In the Alameda County study, eating between meals was associated with poorer health among men, but no such relationship was found in Tecumseh (13). In fact, eating an evening snack more frequently was associated with better health in Tecumseh, and this relationship was significant $(P \leqslant 0.05)$ among women for one chronic disease and one risk factor and among men for two risk factors. In later analyses of the Alameda County data relating the health practices to mortality, the two eating variables, breakfast and snacking, were excluded from the number of health practices score because of lack of significance (22).

The question of whether the seven health practices were so highly interrelated that they measured the same underlying variable was addressed by Belloc and Breslow (2) and comparably analyzed in the Tecumseh data. In general, the seven health practices related to one another in the same manner and to the same degree in both studies. Eight out of twenty-one interrelationships were significant $(P \leqslant$ 0.01 ) in the Tecumseh study, a slightly smaller proportion than was found in the Alameda County study, which had a larger number of cases. The correlations were not very high in either study, indicating that there was not a strong com- 
ponent common to all the variables that could account for their separate relationships to the health status variables.

The health practices index did not relate as strongly to the several Tecumseh health measures as it did to the Alameda County overall health status measure. This may be accounted for by differences in the way the data were collected or the way health status and health practices were defined or by differences between the two communities.

It is apparent that the index is composed in part of practices that are the reverse of several well-recognized risk factors for the health measures used in this study. Further, these health practices, namely desirable weight, not smoking, and moderate or no drinking among men, were the ones that most often showed statistically significant associations with the health measures. An important research question, consequently, would be to determine to what extent combining the practices into an index contributes to the association with health status beyond the contributions of the individual practices.

Another important question is whether the cross-sectional associations found are due to the practices affecting health or vice versa (19). Multivariate analyses would address the first question most appropriately, ascertaining independent and relative contributions of each of the health practices and the index when controlling for other relevant variables. Longitudinal analyses would address the second question. A forthcoming report will describe an analysis using both of these procedures relating the seven health practices to mortality in a subsequent 9 - to 12year period.

Given the level of cross-sectional analysis in this report, a review of Tables $2 \mathrm{a}$ and $b$ and Table 4 provides some indication of how the index compared with the separate health practices in its association with the health status measures.

The index appeared to discriminate for CHD prevalence better than any of the separate practices; among men there was a $9 \%$ difference in prevalence of CHD between those high and low on the index and at most a $6 \%$ difference between those who did or did not have each of the seven practices, e.g., never smoked, $6 \%$ vs $12 \%$. Among women, none of the separate health practices were significantly related to CHD.

The index appeared less strongly associated with hypertension than were two practices, desirable relative weight for men and women and eating breakfast for women. The other five practices were not significantly associated with hypertension in the predicted direction.

Chronic bronchitis showed a strong relationship to the index among men; however when the effects of smoking were removed in the Mantel-Haenszel test, the index was not significantly related to bronchitis.

The index was significantly related to systolic blood pressure in men, but not in women, and not to diastolic blood pressure in either sex. However, two of the separate health practices were related, namely desirable weight and not smoking. For these health measures, the inde: appeared to dilute the basic relationship.

The index was significantly $r:=l a t e d$ to $\mathrm{FEV}_{1}$ in the predicted direction, posi- 
tively, for both men and women. Three separate health practices, also, were strongly related, particularly never smoked. Although the index appeared to discriminate the $\mathrm{FEV}_{1}$ scores of men and women as well as never smoked, analysis of covariance showed that, in fact, the index did not contribute significantly to $\mathrm{FEV}_{1}$ independent of never smoked.

The index was not significantly related to cholesterol and blood glucose but several component practices were related significantly to these risk factors, notably desirable relative weight, never smoked, and moderate or no drinking. For these health status measures, therefore, the index diminished the underlying associations.

In summary, it appeared that the index was an important measure relating health practices cross-sectionally to CHD. For the other health status measures, the relevant single health practice or practices were more important.

Further research is indicated to answer the questions of whether the findings from the Alameda County and Tecumseh studies are replicable in other populations and whether a constellation of health practices leads to better health status and longer life. Further, if a constellation of health practices is beneficial, how are the practices developed and maintained and how do they exert their beneficial influence.

The longitudinal Alameda County studies of mortality appear to indicate that the health practices lead to lower mortality from all causes $(3,7)$. As indicated earlier, a report is forthcoming on a 9- to 12-year mortality follow-up of the Tecumseh Community Health Study population which will also examine this relationship.

\section{ACKNOWLEDGMENTS}

The authors gratefully acknowledge the biomedical consultation of Millicent Higgins and Leon Ostrander, the statistical advice of Richard Landis, and the efforts of Rebecca Turner in preparing the manuscript.

\section{REFERENCES}

1. Belloc, N. B., Breslow L., and Hochstim, J. R. Measurement of physical health in a general population survey. Amer. J. Epidemiol. 93, 328-336 (1971).

2. Belloc, N. B., and Breslow, L. Relationship of physical health status and health practices. Prev. Med. 1, 409-421 (1972).

3. Belloc, N. B. Relationship of health practices and mortality. Prev. Med. 2, 67-81 (1973).

4. Belloc, N. B. Personal behavior affecting mortality, in "Seminar on Biological and Social Aspects of Mortality and the Length of Life, Fiuggi Terme, Italy, May 13-16, 1980."

5. Berkman, L. F., and Syme, S. L. Social networks, host resistance, and mortality: A nine-year follow-up study of Alameda County residents. Amer. J. Epidemiol. 109, 186-204 (1979)

6. Block, W. D., Jarret, J. J., and Levine, J. B. An improved automated determination of serum total cholesterol with a single color reagent. Clin. Chem. 12, 681-689 (1966).

7 Breslow, L., and Enstrom, J. E. Persistence of health habits and their relationship to mortality. Prev. Med. 9, 469-483 (1980).

8. Epstein, F. H., Napier, J. A., Block, W. D., Hayner, N. S., Higgins, M. P., Johnson, B. C., Keller, J. B., Metzner, H. L., Montoye, H. J., Ostrander, L. D., Jr., and Ullman, B. M. The Tecumseh Study. Design, progress, and perspectives. Arch. Environ. Health 21, 402-407 (1970).

9. Higgins, M. W., and Keller, J. B. Seven measures of ventilatory lung function. Amer. Rev. Resp. Dis. 108, 258-272 (1973). 
10. House, J. S., Robbins, C., and Metzner, H. L. The association of social relationships and activities with mortality: Prospective evidence from the Tecumseh Community Health Study. Amer. J. Epidemiol. 116, 123-140 (1982).

11. Mantel, N., and Haenszel, W. Statistical aspects of the analysis of data from retrospective studies of disease. J. Natl. Cancer Inst. 22, 719-748 (1959).

12. Metropolitan Life Insurance Company Statistical Bulletin. "Trends in Average Weights and Heights among Insured Men and Women," Vol. 58, October 1977.

13. Metzner, H. L., Lamphiear, D. E., Wheeler, M. A., and Larkin, F. A. The relationship between frequency of eating and adiposity in adult men and women in the Tecumseh Community Health Study. Amer. J. Clin. Nutr. 30, 712-715 (1977).

14. Montoye, H. J. "Physical Activity and Health: An Epidemiologic Study of an Entire Community," p. 16. Prentice-Hall, Englewood Cliffs, N. J., 1975.

15. Napier, J. A., Johnson, B. C., and Epstein, F. H. The Tecumseh, Michigan Community Health Study, in "The Community as an Epidemiologic Laboratory. A Casebook of Community Studies" (I. I. Kessler and M. L. Levin, Eds.), pp. 25-44. Johns Hopkins Press, Baltimore/London, 1970.

16. Ostrander, L. D., Jr., and Lamphiear, D. E. Coronary risk factors in a community; Findings in Tecumseh, Michigan. Circulation 53, 152-156 (1976).

17. Ostrander, L. D., Jr., Lamphiear, D. E., Carman, W. J., and Williams, G. W. Blood glucose and risk of coronary heart disease. Arteriosclerosis 1, 33-37 (1981).

18. Reiff, G. G., Montoye, H. J., Remington, R. D., Napier, J. A., Metzner, H. L., and Epstein, F. H. Assessment of physical activity by questionnaire and interview. J. Sports Med. Phys. Fitness 7, 135-142 (1967).

19. Thomas, L. Notes of a biology-watcher. On magic medicine. New. Engl. J. Med. 299, 461-463 (1978).

20. Wiley, J. A., and Camacho, T. C. Life-style and future health: Evidence from the Alameda County Study. Prev. Med. 9, 1-21 (1980).

21. Wilson, R. W., and Elinson, J. The National Survey of Personal Health Practices and Consequences, background, selected findings and conceptual issues. Pub. Health Rep. 96, 218-225 (May-June 1981).

22. Wingard, D. L., Berkman, L. F., and Brand, R. J. "A Multivariate Analysis of Health Practices: A Nine Year Mortality Follow-up of the Alameda County Study." Mimeo (1979). 